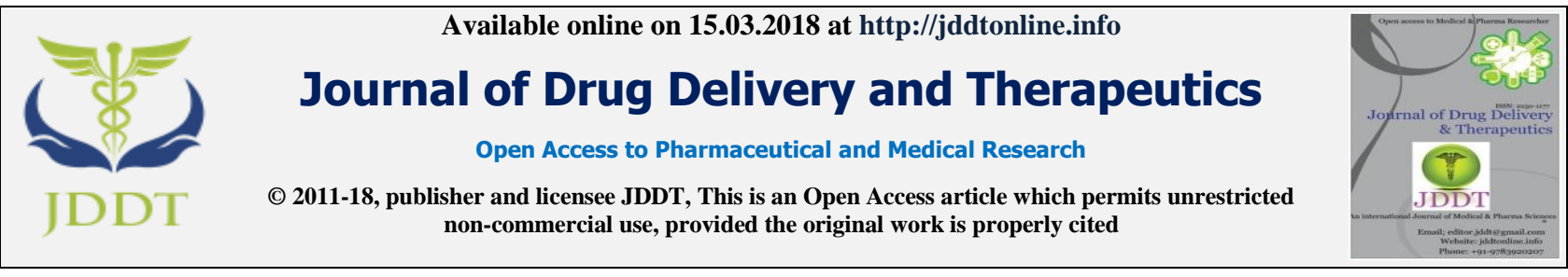

Open $\odot$ Access

Research Article

\title{
CONTRACEPTIVE USE AND FAMILY SIZE PREFERENCES AMONG RURAL WOMEN IN SOKOTO STATE, NIGERIA
}

\author{
Karima Abubakar Tunau ${ }^{1}$, Kehinde Joseph Awosan ${ }^{2}$ \\ ${ }^{1}$ Department of Obstetrics and Gynecology, Usmanu Danfodiyo University, Sokoto, Nigeria \\ ${ }^{2}$ Department of Community Health, Usmanu Danfodiyo University, Sokoto, Nigeria
}

\begin{abstract}
Background: The interplay of high fertility, low contraceptive use and high maternal mortality continues to decimate populations across sub-Saharan Africa. This study aimed to determine contraceptive use and family size preferences among rural women in Sokoto State, Nigeria.

Methods: It was a cross-sectional study conducted in rural communities of Sokoto State, Nigeria, using both quantitative and qualitative methods of data collection. It involved interviews to a random sample of 202 women of child bearing age using semistructured interviewer- administered questionnaire, and focus group discussions among women and men. The quantitative data were analyzed using the IBM SPSS version 17 computer statistical package; while the qualitative data were transcribed, sorted, categorized and analyzed thematically.

Results: The mean age of the women was $27.9 \pm 8.0$ years, most of them had no formal education (85.6\%) and were aged $14-19$ years when they had their first pregnancy $(84.2 \%)$. Of the 202 respondents, only $10(5.0 \%)$ were using modern contraceptives, most commonly pills $4(40.0 \%)$, and injectable contraceptives $4(40.0 \%)$. The main barriers to use of modern contraceptives were religious beliefs, desire for more pregnancies, poor understanding of FP concept/ disapproval by husbands; and lack of communication between couples. Almost all the respondents 197 (97.5\%) preferred large family sizes and most of them 149 (73.8\%) were willing to have as many children as possible.

Conclusion: These findings underscore the need for governments and other stakeholders to make female education the central focus of FP promotion programs, in addition to involving men and religious leaders.
\end{abstract}

Key words: Contraceptive use, modern contraceptives, family size preferences, rural women, Sokoto

Article Info: Received 09 Jan, 2018; Review Completed 11 Feb, 2018; Accepted 11 Feb, 2018; Available online 15 March, 2018

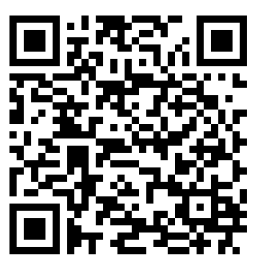

\section{Cite this article as:}

Tunau KA, Awosan KJ, Contraceptive use and family size preferences among rural women in Sokoto State, Nigeria, Journal of Drug Delivery and Therapeutics. 2018; 8(2):1-7

DOI: http://dx.doi.org/10.22270/jddt.v8i2.1663

*Address for Correspondence

Tunau K, Department of Obstetrics and Gynecology, Usmanu Danfodiyo University, Sokoto, Nigeria

\section{INTRODUCTION}

The interplay of high fertility, low contraceptive use and high maternal mortality continues to decimate populations across sub-Saharan Africa. Efforts to bring down the high maternal mortality in the developing countries have not achieved the desired result, and this has become a global public health challenge. More than half a million women, nearly all of them in the developing world, die each year during pregnancy or childbirth. ${ }^{1}$ Another million suffer serious, sometimes permanent pregnancy-related injuries. Much of this suffering and death could be prevented through effective family planning engendered by modern contraception. ${ }^{2}$
The benefits of modern contraception are well-known as family planning (FP) is one of the most important key strategies in preventing the deaths of women, neonates, infants and children. ${ }^{2,3}$ Wide variations exist in contraceptive use and fertility rates in the populations across regions and countries. Fertility levels closely correspond to levels of contraceptive use, and in countries where contraceptive use is low, the fertility rate is high. Developed regions of the world like the United States of America and northern Europe have an average CPR of $73 \%$ and $81 \%$ respectively. ${ }^{4}$ However, the use of modern contraception has been shown to be low in the developing countries which have the poorest maternal and child health indices. Additionally, in sub- 
Saharan Africa, majority of the populace reside in the rural areas where high fertility with its attendant complications is common. ${ }^{5}$ In many African countries, a lineage-based system, usually patrilineal, is commonly practiced. ${ }^{6}$ This traditional familial system favors the concept of continuing family descent, and this is one of the barriers to the introduction of fertility control. Furthermore, African societies dominated by an agrarian life, stress large family size due to high labor demands; thus, high fertility and large families are considered economically rewarding. ${ }^{6,7}$

Nigeria has the second highest maternal mortality rates (MMRs) worldwide and is only next to India. ${ }^{8}$ According to the NDHS $2008,{ }^{9}$ the average MMR in the country is 500 deaths $/ 100000$ live births. The state average MMR is $1500 / 100000$ live births and is even higher in hospital based studies. ${ }^{10}$ For each woman that dies about $30 \%$ are left with serious morbidities. ${ }^{2,11}$ Despite this high maternal mortality, the northwest region, which includes the study area, has the highest fertility rates and lowest acceptance rates for family planning in the country. ${ }^{9,12}$

Research about fertility determinants during the last four decades had focused on economic and socio-cultural factors that affect the attitude of individuals or couples towards family size. The policies and programs intended to bring about a change from large to small family norms cannot succeed without a thorough understanding of these factors in various socioeconomic contexts. ${ }^{7}$ The rural population of Sokoto State, Nigeria, is largely understudied; this study was conducted to determine contraceptive use and family size preferences of rural women in Sokoto State, Nigeria. The findings from the study would be useful to policy makers and program managers in understanding the drivers and developing appropriate strategies for addressing the soaring fertility rates, low contraceptive use, and high maternal mortality in the rural populations of many developing countries.

\section{MATERIALS AND METHODS}

\section{Study Design and Population}

A cross-sectional descriptive study was conducted among women of child bearing age in two Wards of Wurno Local Government Area of Sokoto State between December 2011 and February 2012. Women aged 15 49 years, resident in the area and have given birth to a child were considered eligible for enrollment into the study. The sample size was estimated at 190 using the Fisher's formula for calculating sample size for crosssectional descriptive studies, ${ }^{13}$ a $12.5 \%$ prevalence of modern contraceptive from a previous study, ${ }^{14}$ a precision level of $5 \%$ and an anticipated participant response rate of $95 \%$.

The eligible participants were selected by multi-stage sampling technique. At the first stage, the wards in Wurno LGA of Sokoto State were listed and two were randomly selected from the eleven wards in the LGA by balloting. At the second stage, a line list of all the settlements and their respective populations in each of the two wards selected were made and three settlements from each ward were randomly selected by balloting. At the third stage, house numbering and listing was carried out to determine the number of houses in each of the selected settlements. One in four houses was selected by systematic sampling technique (in direct proportion to the number of houses in the respective settlements) until the required sample size was obtained. One woman of child bearing age was interviewed per house. However, in an event that more than one woman in a house qualified, balloting was done to select who was enrolled into the study. On the other hand, where there was no woman that qualified in the selected house, the next house was used.

\section{Data Collection and Analysis}

Both quantitative (questionnaire administration) and qualitative (focus group discussion) research methods were employed. A set of pretested, semi-structured, interviewer administered questionnaire was used to obtain information on respondent's socio-demographic characteristics, use of modern contraceptives, and family size preference. The questionnaire was translated into Hausa and back translated into English by experts in languages (at the Faculty of Arts, Usmanu Danfodiyo University, Sokoto, Nigeria); the Hausa version was used for data collection. Thematic areas generated from the questionnaire survey were further explored by conducting six focus group discussions (FGDs) using an FGD guide; three among females of reproductive age group (15-49 years) who have ever been married, and were not part of the earlier survey, but resident in the study area; and three among male heads of households. Each FGD group consisted of eight respondents, a note taker, an observer/time keeper and a moderator.

The discussions were conducted in quiet and conducive environment to avoid noise interference and interruption; each session lasted for about 40 minutes to 1 hour. The FGDs were moderated by the principal investigator; the discussions were conducted in the local language (Hausa), and audio-taped with the consent of the participants, while the research assistants serve as note takers and time keepers.

The pretesing of the survey instrument was done on 15 women of child bearing age in Rabah LGA of Sokoto State, no ambiguity was detected and there was no need for any modification. Five midwifery students assisted in data collection after pre-training on conduct of survey research, the objectives of the study, selection of study subjects and use of survey instruments. The quantitative data (questionnaire survey) were analyzed using the IBM SPSS version 17 computer statistical package, and presented as frequencies and proportions; while the qualitative data (FGDs) were transcribed, sorted, categorized and analyzed thematically.

\section{Ethical Consideration}

Institutional ethical clearance was obtained from the Ethical Committee of Usmanu Danfodiyo University Teaching Hospital, Sokoto, Nigeria. Permission to conduct the study was obtained from the Chairman of Wurno LGA of Sokoto State, Nigeria. Advocacy visits were carried out to establish rapport with the leaders of the settlements selected; informed consent was also 
obtained from the study participants before data collection.

\section{RESULTS}

\section{Socio-demographic characteristics of respondents}

All the 202 questionnaires administered were adequately completed and found suitable for analysis, giving a response rate of 100 percent. The ages of the respondents ranged from 15 to 45 years $($ mean $=27.9 \pm$ $8.0)$, and majority $147(72.9 \%)$ of the 202 respondents were aged $20-39$ years. Most of the respondents $(93.6 \%)$ were married, and all of them $(100 \%)$ practiced Islam as religion. Most of the respondents $(85.6 \%)$ had only qurranic education, majority of them $(60.9 \%)$ were traders, while about a third of respondents $(32.2 \%)$ were full-time housewives (Table 1).

Table 1: Socio-demographic characteristics of respondents

\begin{tabular}{ll}
\hline Variables & $\begin{array}{c}\text { Frequency }(\boldsymbol{\%}) \\
\mathbf{n = 2 0 2}\end{array}$ \\
\hline Age groups (in years) & \\
$15-19$ & $32(15.8)$ \\
$20-29$ & $76(37.7)$ \\
$30-39$ & $71(35.2)$ \\
40 and above & $23(11.3)$
\end{tabular}

\section{Marital status}

Single

Married

$189(93.6)$

Divorced

$6(3.0)$

Widowed

$6(3.0)$

\section{Religion}

Islam

Christianity

$202(100)$

$0(0)$

\section{Educational status}

None

Quranic only

Primary

Secondary

Tertiary

$3(1.5)$

\section{Occupation}

Unemployed

Student

Business/ trading

Civil servant

Farmer

Full-time housewife

\section{Respondents' obstetric history}

The parity of the women ranged from 1 to 15 (mean = $4.8 \pm 3.3)$, and majority, $116(57.4 \%)$ of the 202 respondents have delivered $1-4$ times. The respondents' ages at first pregnancy ranged from 14 to 29 years $($ mean $=16.4 \pm 3.0)$, and most of them 170 $(84.2 \%)$ were aged 14 to 19 years when they had their first pregnancy. While the respondents had their last

child birth 1 to 20 years ago $($ mean $=2.9 \pm 3.4)$, most of them $183(90.6 \%)$ had their last child birth $1-5$ years ago. The respondents have 1 to 10 living children (mean $=3.8 \pm 2.3$ ), and about a quarter, $52(25.7 \%)$ of the 202 respondents have 6 to 10 living children (Table 2 ).

Table 2: Respondents' obstetric history

\begin{tabular}{lc}
\hline Variables & $\begin{array}{c}\text { Frequency }(\%) \\
\mathbf{n = 2 0 2}\end{array}$ \\
\hline Parity & $116(57.4)$ \\
$1-4$ & $66(37.2)$ \\
$5-9$ & $20(9.9)$ \\
$\geq 10$ & $4.8 \pm 3.3$
\end{tabular}

Age at first pregnancy (in years)

$14-19$

$170(84.2)$

$20-25$

$31(15.3)$

$26-31$

$1(0.5)$

Mean

$16.4+3.0$

Last child birth (in years)

1 - 5

$6-10$

183 (90.6)

9 (4.5)

$11-15$

$6(3.0)$

$16-20$

4 (2.0)

Mean

$2.9 \pm 3.4$

Number of living children

1- 5

150 (74.3)

$6-10$

52 (25.7)

Mean

$3.8+2.3$

\section{Use of family planning among respondents}

Less than a fifth, $31(15.3 \%)$ of the 202 respondents have ever used any family planning method, and only a few $16(7.9 \%)$ currently use a family planning method. Of the 16 respondents that currently use a family planning method, $10(62.5 \%)$ reported use of modern contraceptives. It therefore means that only $10(5.0 \%)$ of the 202 respondents currently use modern contraceptives. Of the 10 respondents that currently use modern contraceptives, the most commonly used modern contraceptives were pills $(40.0 \%)$ and injectable contraceptives $(40.0 \%)$ as shown in Table 3.

The main reasons cited for not using family planning include religious beliefs $48(25.8 \%)$, desire for more pregnancies $46(24.7 \%)$, and husband's disapproval 37 $(19.9 \%)$. Other reasons given for not using family planning are as shown in Table 4.

In the FGD sessions among women, side effects of family planning, religious beliefs and husband's disapproval were the major reasons given for not using family planning; and for discontinuation of use among those that were already using it. They believed that use of modern family planning methods is often associated with health problems such as troublesome vaginal bleeding, weight gain, damage to the womb and sterility. A 37-year old non-user of FP in the women group said:

"Those who use FP become very fat and they keep on menstruating all the time, some for months at a time". 
Another 26 year old mother of 4 related her experience following use of FP:

"I kept on bleeding and my husband was very angry, he threatened me and prevented me from taking any more injections".

Many of the female participants in the FGD sessions who use FP said they use it secretly, the reason being that their spouses objected to its use, and also because users of FP were regarded as being promiscuous by the community members. In addition, in-laws could instigate marital disharmony if they become aware of FP use by the woman. A participant said:

'They really look down on you when they know you are using FP, you are regarded as a loose woman or even a whore'

Further probing at the FGD sessions among men revealed that the main reasons for disapproval of FP by husbands were religious beliefs and the lack of proper knowledge and understanding of the concept of modern FP. The general belief was that the use of FP to limit childbearing was against the tenets of Islam. A cleric among the participants said:

'The teaching in Islam is to marry and procreate. Therefore, not doing this is seen as going against the law of nature and FP is regarded as a 'white man's ploy' to reduce the number of Muslims'.

A 59-year old participant with 2 wives and 12 children opined that:

'FP is just a way of killing our children or stopping us from giving birth and in fact we remove our children from the school of any teacher that is practicing FP'.

Many of the male participants said that they have never discussed issues regarding family planning with their wives because they believed their wives could misunderstand their motives for doing so. Some of the men admitted that they would agree to the use of FP if their wives make a request, while many of the women admitted that they would use FP if their husbands instruct them to do so. A 38-year old male participant said:

'If any of my wives asks me if she can use FP, I will allow her to use it but if I start talking about it she will misunderstand me and think I only want another woman's children'.

Table 3: Use of family planning among respondents

\begin{tabular}{lc}
\hline Variables & $\begin{array}{c}\text { Frequency(\%) } \\
\mathbf{n = 2 0 2}\end{array}$ \\
\hline $\begin{array}{l}\text { Ever used family planning }(\mathbf{n}=\mathbf{2 0 2}) \\
\text { Yes }\end{array}$ & $31(15.3)$ \\
No & $171(84.7)$ \\
Current use of family planning & \\
(n= 202) & \\
Yes & $16(7.9)$ \\
No & $186(92.1)$ \\
& \\
Method of family planning & \\
currently used (n= 16) & \\
Traditional & $6(37.5)$ \\
Modern contraceptives & $10(62.5)$ \\
Modern contraceptives currently & \\
used (n = 10) & \\
Pills & \\
Injectable contraceptives & $4(40.0)$ \\
Intrauterine device & $4(40.0)$ \\
Implants & $1(10.0)$ \\
\hline
\end{tabular}

Table 4: Reasons for not using family planning

\begin{tabular}{lc}
\hline Reason for not using modern contraceptives & $\begin{array}{c}\text { Frequency (\%) } \\
\mathbf{n = 1 8 6}\end{array}$ \\
\hline Pregnant already & $5(2.7)$ \\
Desire to get pregnant & $46(24.7)$ \\
Religious beliefs & $48(25.8)$ \\
Husband disapproval & $37(19.9)$ \\
Side-effects of contraceptives & $6(3.2)$ \\
Long distance to source of family planning services & $2(1.1)$ \\
Attitude of service providers & $3(1.6)$ \\
Fear of sterility & $3(1.6)$ \\
Difficulty in using the methods available & $3(1.6)$ \\
No specific reason & $16(8.6)$ \\
Natural spacing between births & $7(3.7)$ \\
Unaware of family planning & $10(5.4)$ \\
\hline
\end{tabular}

\section{Respondents' family size preferences}

Almost all the respondents $197(97.5 \%)$ preferred large family sizes; and majority, $149(73.8 \%)$ of the 202 respondents intend to have as many children as God gives to them. Close to a fifth of respondents (15.3\%) intend to have 6 to 10 children, a few of them $(8.4 \%)$ intend to have 11 to 15 children, while only 5 (2.5\%) of the 202 respondents intend to have 5 children and below.

The main reasons cited for their desire for high fertility include, not knowing which one will survive and do well later in life 99 (49.0\%), love for children 43 $(21.3 \%)$, being one of their religious obligations 41 (20.3\%), to have more power in the home/ larger share 
of inheritance when the husband dies 31 (15.4\%), and desire for male children 27 (13.4\%). Other reasons cited are as shown in Table 5.

Most the participants at all the FGDs sessions desired large families. The main reasons for this desire were the uncertainty of childhood survival, the security children provide in old age and the fact that children would pray for them when they die. A 35-year old male participant said:

'We need to have as many children as possible as we don't know which one God will leave for us and which one he will bless among them'.
Furthermore, women in polygamous unions consider having many children as a source of power in the household, in addition to having substantial inheritance at the demise of their spouses. A female participant said:

'There are women that don't want FP because they want to have many children, there is competition between cowives and the ones with the highest number of children have more power. They have a saying that' yaye babu chiki kauyanci' (i.e. weaning one baby without being pregnant is a provincial behavior').

Table 5: Respondents' family size preferences

\begin{tabular}{lc}
\hline Variables & $\begin{array}{c}\text { Frequency (\%) } \\
\mathbf{n}=\mathbf{2 0 2}\end{array}$ \\
\hline Number of children respondents intend to have & \\
Only God knows & $149(73.8)$ \\
$1-5$ & $5(2.5)$ \\
$6-10$ & $31(15.3)$ \\
$11-15$ & $17(8.4)$ \\
& \\
*Reasons for high fertility & \\
Don't know which one will survive and be useful & $99(49.0)$ \\
Love for children & $43(21.3)$ \\
It is advocated by my religion & $41(20.3)$ \\
The more the number of children the more power a & $31(15.4)$ \\
woman has/the more her share of inheritance when & \\
her husband dies & $27(13.4)$ \\
Desire for male children & $12(5.9)$ \\
Competition between co-wives & $10(5.0)$ \\
Children pray for their parents when they die & $8(4.0)$ \\
It is expected traditionally & $6(3.0)$ \\
Ignorance about family planning & $5(2.5)$ \\
Inability to refuse sex & \\
\hline
\end{tabular}

*Multiple responses allowed

\section{DISCUSSION}

Most of the participants in this study $(84.2 \%)$ had their first baby at a relatively young age of 14 to 19 years, and a substantial proportion of participants (25.7\%) have $6-10$ children (with a mean parity of $4.8 \pm 3.3$ ). The high fertility among the women in this study is in consonance with the high fertility among women in Nigeria. Reports from the Nigeria Demographic and Health Survey (NDHS) 2013 showed that, women in Nigeria currently have an average of 5.5 children, and it is still very close to the 5.7 children per women reported in 2003 and $2008 .{ }^{15}$ The high fertility of the women in this study could be related to their poor educational attainment as majority of them $(89.1 \%)$ did not have any formal education, and it reflects the documented low female enrolment into basic formal education in Sokoto State, Nigeria, particularly in the rural communities. ${ }^{16}$ This is further supported by the findings from the NDHS 2013 which showed that north-western Nigeria (the study area) had the highest proportion of young motherhood $(36.0 \%)$ in the country. In addition, half $(50 \%)$ of adolescent women with no education have begun childbearing, compared with $2 \%$ of women with more than secondary education. ${ }^{15}$ Another contributory factor is the prevalent culture of early marriage for the girl child in northern Nigeria; they therefore start childbearing as teenagers and end up having many children within the period of their reproductive age. This is supported by the finding in a study in Osogbo, southwestern Nigeria that found that better-educated women have lower fertility, broader knowledge of family planning, higher socioeconomic status and less fatalistic attitudes towards reproduction than do less educated women. ${ }^{17}$

Use of a family planning method was low (7.9\%), and use of modern FP was abysmally low (5.0\%) among the respondents in this study. While the $5.0 \%$ use of modern FP obtained is much higher than the $1.9 \%$ prevalence reported in a previous National Demographic and Health Survey in Sokoto, Nigeria (the study area) in 2003, ${ }^{18}$ and suggests an improvement in the acceptance of modern contraceptives among women in Sokoto, Nigeria, it is just half the $10 \%$ prevalence of modern contraceptive use in the country in $2008^{15}$; and it is far below the $12.5 \%$ prevalence reported in a study among married women in Samaru community, Zaria (also in north-western Nigeria). ${ }^{14}$ In contrast to the low prevalence $(7.9 \%)$ of use of a family planning method 
among the respondents in this study, other studies conducted in the southern part of Nigeria reported relatively high prevalence of use of a family planning method; these include studies conducted in Enugu, Nigeria $^{19}$ and Nnewi, Nigeria ${ }^{20}$ that reported $20 \%$ and $44.0 \%$ prevalence of use of a FP method respectively. Contraceptive use among women in Nigeria has been found to be associated with their level of education; an estimated $37 \%$ of married women with secondary education use any family planning method, compared with $3 \%$ of married women with no education. ${ }^{15}$ The disparities in contraceptive prevalence in the geopolitical zones of the country, and between the rural and urban populations of the respective zones evidently correlate perfectly with the disparities in the educational attainment of women in these communities.

Pills and injectable contraceptives were the main methods of modern contraceptives used by the respondents in this study, while one respondent each also used intrauterine devices and implant. Women preference for injectable contraceptive has been attributed to its relatively long duration of action (at least 2 months) and the possibility of keeping their husbands out of the picture should they disagree on use of modern contraceptives. ${ }^{21,22}$ This is corroborated by the findings from the FGDs in which many of the women that use modern contraceptives said they do so secretly without allowing their husbands to know. Contrary to the finding in this study, a recent health facility based study in Sokoto (the study area) reported implant as the most commonly used contraceptive among the women studied. ${ }^{23}$ Also, Debb ${ }^{24}$ in India and He et $\mathrm{al}^{25}$ in China found that the most popular FP methods among the population studied were sterilization and intrauterine devices (IUDs). Permanent methods are not popular in the study area partly because of religious beliefs and also the general aversion to surgery.

The major barriers to use of modern FP among the respondents in this study were religious beliefs, desire for more children and husband's disapproval. An interesting finding from the FGD sessions is the fact that a good number of the men were actually in support of the use of modern contraceptives by their wives but they were reluctant to discuss it with them to avoid being misunderstood. Likewise, the women were reluctant to discuss it with their husbands, out of fear of being misunderstood; they erroneously assumed that their husbands were against the use of modern FP, and so the few who used it among them did so secretly. This is similar to what obtains in Kano, Nigeria ${ }^{26}$ and Maiduguri, Nigeria ${ }^{27}$ which share similar cultural characteristics as the study area. In Kano, Nigeria, Izugbara et al. ${ }^{26}$ observed that there was lack of spousal communication about FP as the men felt the women should bring it up and the women felt it was the duty of the men to bring up such issues. So at the end of the day the issue is not discussed at all even if both of them desire it. A study conducted in Kenya also reported lack of couple agreement and poor communication as major barriers to use of modern FP. ${ }^{28}$ The relationship between communication between couples and use of FP is further elucidated in a study in Ghana ${ }^{29}$ that found that married women who discussed family planning with their partners were three times more likely to be current contraceptive users. The study also attributed the limited impact of family planning programs in Ghana and most of sub-Saharan Africa to the continued neglect of men as equal targets of such programs. These findings underscore the need to target couples for FP promotion interventions rather than only women, who are seen as the end users.

The respondents in this study predominantly $(73.8 \%)$ preferred large family sizes, as they intend to have as many children as God gives to them. The main drivers for this desire for many children were the uncertainty of childhood survival, love for children, religion and power play within the household. Love for children is a common cultural trait of all the ethnic groups in Nigeria and other countries in sub-Saharan Africa, and it has been attributed to their belief in God's bounty, the pleasure of having children and the security that children confer at old age. ${ }^{30}$ This is corroborated by the high fertility rates in Nigeria ( 5.5 births per woman) and other sub-Saharan Africa countries including Ghana, Senegal, Mali and Niger Republic with 4.0, 5.5, 6.6 and 7.6 births per woman respectively, ${ }^{15}$ Having many children may not be peculiar to Africans only as Bachock et al. ${ }^{31}$ in rural Malaysia found that many Malay families consider having many children to represent wealth and security later in life, because they can help with chores and provide support to their parents as they age.

The respondents' concern over childhood survival is genuine in view of the persistently high neonatal, infant and childhood mortality rates of 37, 69 and 128 per 1,000 live births respectively in Nigeria. ${ }^{15}$ In addition, the north-west zone of the country (the study area) had the highest under-5 mortality rate in Nigeria at 185 deaths per 1,000 live birth, compared to 90 per 1,000 live births in the south-west zone; and it is far above the estimated under-5 mortality rate of 128 deaths per 1,000 live birth in the country. ${ }^{15}$ Ignorance is one of the explanations behind the fatalism expressed over reproductive matters. It is ironical that in traditional societies that love children so much, there is a general sense of helplessness in the matters of survivorship of infants and children into adulthood. This sense of helplessness is popularly called the "what God wills syndrome". ${ }^{32}$ Reports from the NDHS $2013^{15}$ established strong links between childhood survival and maternal education. Under-5 mortality among children born to mothers with no education (180 deaths per 1000 live births) was almost twice that of children born to mothers with secondary education (91 deaths per 1000 live births), and three times that of children born to mothers with more than secondary education (62 deaths per 1,000 live births). These findings bring to the fore the crucial role of female education in facilitating acceptance and use of FP, and they underscore the need for government and other stakeholders to make female education the central focus of FP promotion programs, rather than just periodic sensitization programs or provision of FP commodities. 


\section{CONCLUSION}

This study showed an abysmally low use of modern contraceptives and desire for very large family sizes among rural women in Sokoto, Nigeria. The main barriers to use of modern contraceptives were religious beliefs, desire for more pregnancies, poor understanding of FP concept/ disapproval by husbands; and lack of communication between couples. In addition to involving men and religious leaders, governments and other stakeholders should make female education the central focus of FP promotion programs.

\section{REFERENCES}

1. Ronsmans C, Graham WJ. On behalf of The Lancet Maternal Survival Series Steering Group. Maternal mortality: who, when, where, and why. Lancet 2006; 368:1189-1200.

2. Smith R, Ashford 1, Gribble J, Clifton D Family planning saves lives. 4th edn Population Reference Bureau.2009; 1 22.

3. Stover J, Ross J. How increased contraceptive use has reduced maternal mortality. Mater Child Health J 2010; 14(5): 687-95 doi: 10.1007/s 10995-009-0505-y.

4. Population Reference Bureau. 2012 World Population Data Sheet. Available at: www.prb.org/pdf12/2012-population-datasheet eng.pdf.

5. Govindasmy P, Malhotra A. Women's position and family planning in Egypt. Stud Fam Plann 1995; 27(6): 328-40.

6. Caldwell JC, Caldwell P. The cultural context of high fertility in sub-Saharan Africa. Pop Dev Rev 1987; 13(3):409-437.

7. Mairiga AG, Kullima AA, Bako B, Kolo AA. Sociocultural factors influencing decision-making related to fertility among the Kanuri tribe of northeastern Nigeria. Afr J Prm. Health Care Fam Med 2010; 2(1):094.

8. United Nations. World Population Prospects. United Nations Department of Economic and Social Affairs, Population Division; 2011. Pop/db/cp/rev 2010

9. NPC and ICF Macro. Nigeria demographic and health survey 2008. Abuja, Nigeria: National Population Commission and ICF Macro; 2009.

10. UNFPA Nigeria. Reproductive health and gender indicators: Report on 2004 baseline survey of UNFPA assisted states in Nigeria. Abuja, Nigeria: United Nations Fund for Population Activities, Nigeria; 2005.

11. Goliber T, Sanders R, Ross J. Analyzing family planning needs in Nigeria: lessons for repositioning family planning in sub-Saharan Africa. Washington, DC: Futures group, Health Policy Initiative, task order 1; 2009

12. Akunga A. Northern Nigeria: Approaches to enrolling girls in school and providing meaningful education to empowe change. United Nations Girls' Education Initiative; 2010. Available at: http://www.e4conference.org/wp-content/

13. Ibrahim Taofeek. Research methodology and dissertation writing for health and allied health professionals. Abuja: Cress Global Link Limited; 2009.

14. Aliyu AA, Shehu AU, Sambo MN, Sabitu K. Contraceptive knowledge, attitudes and practice among married women in Samaru community, Zaria, Nigeria. East Afr J Public Health 2010; 7(4):342-4.

15. National Population Commission [Nigeria] and ICF International. Nigeria Demographic and Health Survey 2013. Rockville, Maryland, USA: National Population Conmmission and ICF International; 2014.

16. MoE, Sokoto State-GPE. Strategic Education Sector Plan 2011-2020. Ministry of Education, Sokoto State, Global Partnership for Education. Avaialble at: http://www.global partnership.org/fr.../46613.

17. Adebimpe WO, Asekun-Olarinmoye E, Bamidele JO, Abodunrin O. A comparative study of sociodemographic

\section{Competing Interests: Nil.}

Authors' Contributions: This work was carried out in collaboration between both authors. Both authors (KT and KJA) designed the study, performed data collection, analysis and interpretation, and drafted the manuscript. Both authors read and approved the final manuscript.

Acknowledgements: The authors appreciate the Chairman of Wurno LGA of Sokoto State, Nigeria, the traditional leaders of the settlements used, and all the study participants for their cooperation.

determinants and fertility pattern among women in rural and urban communities in southwestern Nigeria. Cont J Med Res $2011 ; 5(1): 32-40$

18. NPC and ICF Macro. Nigerian Demography and Health Survey 2003 key findings. Abuja, Nigeria and Maryland, USA: National Population Commission Abuja and ICF Macro; 2003.

19. Onwuzurike BK, Uzochukwu BC. Knowledge attitude and practice of family planning among women in a high-density low-income urban area of Enugu, Nigeria. Afr J Reprod Health 2001; 5(2):83-89.

20. Ugboaja JO, Nwosu BO, Ifeadike CO, Nnebue CC, ObiNwosu AI. Contraceptive choices and practices among urban women in southeastern Nigeria. Niger J Med 2011; 20(3): 3605

21. Kebede Y. Contraceptive prevalence in Dembia district, northwest Ethiopia. Ethiopian J Health Dev 2006; 20(1):32-38.

22. Mqhayi M, Smit J, McFadyen M, Beksinka C, Conolly C, Zuma K, Morono C. Missed opportunities: emergency contraception utilization by young South African women. Afr J Reprod Health 2004; 8(2):137-144.

23. Shehu CE, Burodo AT. Contraceptive choices among women attending the fertility research unit of Usmanu Danfodiyo University Teaching Hospital, Sokoto. Sahel Med J 2013; 16(3):93-96.

24. Deb R. Knowledge, attitude and practices related to family planning methods among the Khasi tribes of east khasi hills Meghalaya. Anthropol 2010; 12(1): 41-45.

25. He H, Фstbye T, Daltveit AK. Reproductive and family planning history, knowledge, and needs: a community survey of low-income women in Beijing, China. BMC Women's Health 2009; 9:23. DOI: 10.1186/1472-6874-9-23.

26. Izugbara $\mathrm{CO}$, Ezeh AC, Ibisomi L, Mberu B. Change and continuity in reproductive norms and behavior: A Northern Nigeria study. Nairobi, Kenya: African Population and Health Research Centre; 2009

27. Isuigo-Abanihe UC. Male role and responsibility in fertility and reproductive health in Nigeria. Lagos, Nigeria: Ababa Press; 2003

28. Kamau R, Karanja J, Sekadde-Kigondu C, Runinjo K, Nicholas D, Liku J. Barriers to contraceptive use in Kenya. East Afr Med J 1996; 73(10): 651-9.

29. Tawiah EO. Factors affecting contraceptive use in Ghana. J Biosoc Sci 1997; 29(2):141-9.

30. Ademuwagun ZA. The challenge of the coexistence of orthodox and traditional medicine in Nigeria. In: Ademuwagun ZA, Ayoade JA, Harrison IE, Warren DM, ed. African therapeutic systems. Waltham Massachusetts: Crossroads Press; 1979. pp 165-70.

31. Bachok N, AbdulRazak A, Ismail NM. Acceptance and knowledge of family planning among Muslim women in rural villages of Kelantan. JIMA 2007; 39:109.

32. Adeokun LA. Sociocultural aspects of family planning and HIV/AIDS in Nigeria. Ibadan, Nigeria: ABBI Books; 2009. 